\title{
Doxorubicin cardiotoxicity and target cells: a broader perspective
}

\author{
Antonella De Angelis ${ }^{*}$, Konrad Urbanek $^{\dagger}$, Donato Cappetta, Elena Piegari, Loreta Pia Ciuffreda, Alessia Rivellino, \\ Rosa Russo, Grazia Esposito, Francesco Rossi and Liberato Berrino
}

\begin{abstract}
The cardiotoxicity of doxorubicin is becoming an interdisciplinary point of interest given a growing population of cancer survivors. The complex and not completely understood pathogenesis of this complication makes difficult to design successful preventive or curative measures. Although cardiomyocyte has been considered a classical cellular target, other cells including various types of undifferentiated cells are involved in myocardial homeostasis. Such perspective may shed light on previously unrecognized aspects of cardiotoxicity and promote new experimental and clinical cardioprotective strategies. In this review, different cellular targets of doxorubicin are discussed with the focus on cardiac progenitor cells, oxidative stress, DNA damage, senescence and apoptosis all of which contribute to their compromised functional properties.
\end{abstract}

Keywords: Doxorubicin cardiotoxicity, Myocardial homeostasis, Progenitor cells

\section{Background}

Anthracyclines, including doxorubicin (DOX), discovered nearly a half-century ago, are still a backbone of life-saving chemotherapy schemes [1]. Shortly after their introduction, the cardiovascular toxicity has been noticed and reported [2-5]. Although this class of drugs has been used and studied for decades, the pathogenesis of cardiotoxicity remains not completely understood. Its complex and still partially obscured nature makes difficult to design successful preventive or curative measures. Nowadays, given the accumulating population of cancer survivors that have been exposed to the treatment as children or adults, this problem is becoming an interdisciplinary point of interest. In this regard, relatively recent cardio-oncology initiative aims to respond to the growing needs to further clarify pathophysiology and to uniform the guidelines regarding diagnosis, prevention, management and follow-up of anthracycline cardiotoxicity [6].

Unfortunately, contrary to the common perception, the dimension of the problem is by no means small. One of the recent analyses reported the incidence of respectively subclinical and overt cardiotoxicity in $17.9 \%$ and

\footnotetext{
* Correspondence: antonella.deangelis@unina2.it

${ }^{\dagger}$ Equal contributors

Department of Experimental Medicine, Section of Pharmacology, Second

University of Naples, via Costantinopoli 16, 80138 Naples, Italy
}

in $6.3 \%$ of cancer patients treated with anthracyclines after 9 years follow-up [7]. In another study, scheduled echocardiography revealed left ventricular ejection fraction reduction in $9 \%$ of adult patients within the first year after chemotherapy [8]. Moreover, with the use of alternative echocardiographic parameters as myocardial strain, high prevalence of cardiac dysfunction associated with anthracycline treatment has been reported, varying from nearly $30 \%$ in adult survivors of childhood cancer to as much as $60 \%$ in children $[9,10]$. Taking to account the growing number of cancer survivors, that only in USA is predicted to reach about 19 million by 2024 [11], post-chemotherapy monitoring together with continued research on cardiotoxicity of anti-neoplastic drugs are warranted.

\section{Cardioprotective strategies}

The first step to diminish the incidence of DOX cardiotoxicity is to use doses lower than $450 \mathrm{mg} / \mathrm{m}^{2}$, although it is becoming more and more apparent that while lowered cumulative dose causes a significant reduction of ontreatment events, no reduction of late-onset complications has been observed [12]. Therefore, there is no dose of DOX that can be considered absolutely safe. 
Up to date, a series of strategies have been used in attempt to reduce or prevent deleterious effects that anthracyclines have on the heart. Proposed pharma cokinetics-based approaches consist of changing administration schedule by replacing bolus with slow infusion and switching from conventional to liposomal formulations [13]. In adults, continuous infusion that lowers peak concentration without affecting the dose may reduce cardiotoxicity without compromising anticancer activity [14]. However, the elevated costs of longer hospitalization and risk of infections have limited this method [15]. Additionally, in children, continuous infusion did not provide cardioprotective benefits [16]. Due to their peculiar distribution profile, uncoated or pegylated liposomal anthracyclines proved to be as effective as standard preparations but associate with minor cardiotoxic effects $[17,18]$. Despite the availability of several formulations (i.e. liposomal DOX, pegylated liposomal DOX and liposomal daunorubicin), their cost and the lack of randomized trials in children with cancer [19], restricts their use to limited oncologic settings [20]. Another strategy is to utilize less cardiotoxic anthracycline derivatives, such as epirubicin or idarubicin, although their better safety profile is yet to be proven [21, 22]. However, it is often necessary to augment the dose to ensure the equivalent activity as that of DOX, thus increasing the risk of cardiotoxic events [23].

Other measures aim to prevent cardiotoxicity by interfering with molecular and cellular mechanisms altered by anthracycline. Dexrazoxane is the only approved cardioprotective agent used in patients exposed to anthracyclines [13], with a proven efficacy in childhood and adulthood $[24,25]$. As an iron chelating agent, it interferes with iron-dependent redox reactions thereby decreasing reactive oxygen species (ROS) production and tissue damage acting as free-radical scavenger [26]. More recently, dexrazoxane was shown to inhibit DNA topoisomerase II $\beta$, thus preventing anthracycline from binding to the enzyme and consequent DNA double strand breaks [27]. A single, not confirmed report, which claimed a possible interaction of dexrazoxane with anti-tumour efficacy of anthracycline [28] together with another concern regarding the potential risk of a second malignancy in paediatric patients $[24,29,30]$ led regulatory agencies to limit its clinical use [31]. However, this opinion may be worth to be re-evaluated [20,32]. Other compounds with antioxidant properties, such as probucol, vitamin E, Lcarnitine, coenzyme $\mathrm{Q}$, glutatione and $\mathrm{N}$-acetylcystein were tested in experimental and clinical settings with inconclusive findings $[13,33]$.

At present, there are no specific clinical practice guidelines and the treatment, as for all patients with heart failure, includes a combination of $\beta$-blockers, ACE-inhibitors, angiotensin receptor blockers, diuretics, nitrates, and hydralazine [34] and, for end-stage failure, heart transplantation. Among those, ACE-inhibitors and $\beta$-blockers showed significant cardiac protection in patients under anthracycline treatment $[8,35,36]$. Since the whole class does not share this effect, their action is probably not related to adrenoceptor blockage. In fact, carvedilol diminishes ROS formation in DOX-treated cardiomyocytes [37], whereas nebivolol prevents generation of peroxynitrite and NO synthase uncoupling [38].

Overall, available cardioprotective measures that operate directly or indirectly at the most accepted upstream phenomenon of ROS generation and oxidative stress [39] has not solved the clinical problem. Additional studies are necessary to develop alternative strategies for the heterogeneous patient population that carry for the rest of their lives the burden of higher risk of heart failure.

\section{Cellular targets}

The myriad of studies aiming to explore cellular and molecular phenomena that may be clinically relevant has been focused on a cardiomyocyte and were extensively reviewed elsewhere [40, 41]. However, although cardiomyocyte has been considered a classical cellular target, other cell types such as cardiac fibroblasts, endothelial cells and vascular smooth muscle cells are also present (and are numerically prevalent) within the myocardium. Moreover, a notion that various types of undifferentiated cells can also be involved in the homeostasis of cardiac tissue certainly adds a new level of complexity to the understanding of myocardial biology. Because these elements dynamically interact in order to respond to changes in homeostatic needs and pathological stimuli, the structural and functional relationship between different cellular components cannot be dismissed. These considerations may offer the possibility to study previously unrecognized aspects of cardiotoxicity [42].

\section{Cardiac progenitor cells}

The adult heart contains a population of primitive cells that in normal conditions contribute to tissue homeostasis, while in pathological states mediate myocardial regeneration [43-46]. Adult cardiac progenitor cells (CPCs) express c-kit, are self-renewing, clonogenic and multipotent, give rise to cardiomyocytes, smooth muscle cells and endothelial cells. CPC involvement has been documented in aging and in several pathological conditions also in humans [47-52], indicating this cells as a pathophysiological target. Furthermore, senescence of stem cell population contributes to the onset and progression of heart failure $[47-49,51-54]$. In this view, relatively recent studies have shown that cardiotoxicity of the anthracycline is not restricted to cardiomyocytes but affects also resident $\mathrm{CPCs}$, proposing an additional mechanism underlining the pathophysiology of DOX-induced cardiomyopathy 
[55-58]. In a model of anthracycline-induced heart failure, DOX inhibited CPC proliferation, that in combination with the accumulation of oxidative DNA damage, growth arrest, cellular senescence and apoptosis led to an almost complete depletion of the CPC pool. The lack of activation of CPCs interfered with the turnover of cardiomyocytes in the presence of myocyte death and senescence [56].

The clinical relevance of these animal findings was established by the study performed on hearts obtained at autopsy from oncologic patients who died of heart failure developed after treatment with chemotherapeutic regimens including anthracyclines. The hearts of patients with anthracycline cardiomyopathy contained higher fraction of senescent human CPCs (hCPCs) when compared with age-matched controls that died from non-cardiovascular causes [57]. The senescence marker $\mathrm{p} 16^{\mathrm{INK} 4 \mathrm{a}}$ was present in the vast majority of hCPCs, exceeding the values reported for chronologic aging and other cardiomyopathies [47, 48, 54]. These observations were complemented by the in vitro tests showing that isolated hCPCs were sensitive to DOX, and their survival, growth and function were negatively affected. DNA damage in hCPCs, shown by the expression of a phosphorylated form of histone $\mathrm{H} 2$ $(\gamma \mathrm{H} 2 \mathrm{AX})$, and the accumulation of senescent cells could therefore affect cardiac homeostasis increasing susceptibility to the myocardial damage also in the human heart.

\section{DOX and functional properties of CPCs}

To fulfil their role, the viable progenitor cells need to reach the area of injury and give rise to differentiated progeny capable to repair the damage. IGF-1/IGF-1R and $\mathrm{HGF} / \mathrm{c}-\mathrm{Met}$ systems are determinants of CPC function favouring CPC-mediated myocardial regeneration $[59,60]$. Stimulation of IGF-1R activates mitogenic and antiapoptotic effects [59, 61, 62] while c-Met is the receptor for HGF, a cytokine that stimulates cell migration to the sites of injury [62, 63]. DOX reduces the expression of IGF$1 \mathrm{R}$ and c-Met in hCPCs and this negative effect persists with time [57]. Although DOX does not abolish differentiation capacity of hCPCs, the majority of committed progeny deriving from DOX-treated progenitors prematurely inherited a senescent phenotype. In addition to $\mathrm{CPC}$ death and senescence, DOX negative interference with growth factor systems that regulate cardiac repair, may further aggravate the inadequate response of the human heart to stress. The functional inferiority of hCPCs exposed to DOX was confirmed in vivo in an animal model of anthracycline cardiomyopathy. In contrast to experimental therapy with healthy cells, the use of DOX-treated hCPCs did not lead to structural and functional recovery and the survival benefits were not observed [58].

\section{CPCs and late onset cardiotoxicity}

The unresolved enigma however, is that the time elapsed between therapy with anthracyclines and onset of cardiac complications varies from months to years or even decades. It is possible that minor noxious events, that in the healthy person would not have severe consequences, can trigger pathophysiological cascade in subjects treated with anthracyclines. Pre-existing conditions or co-morbidities that develop during the post-chemotherapy period can additionally increase the risk of the cardiovascular sequel. An intriguing working hypothesis is that therapy with anthracyclines can leave a specific cellular "signature" to the heart that persists with time and reveals itself after the latent and asymptomatic period with the devastating outcome. In this scenario, a long-lasting damage of a quiescent progenitor cell can serve as a "carrier" of this information. This concept was tested in the study of lateonset cardiotoxicity in mice injected with DOX shortly after birth [55]. In adult age, no difference in cardiac function was observed and the hearts from DOX-treated mice appeared morphologically normal without degenerative changes suggestive of DOX-mediated toxicity. However, the juvenile DOX exposure reduced coronary flow, vessel branching and capillary density, suggesting that juvenile DOX exposure might affect vascular development. Interestingly, hearts of adult mice injected with DOX in juvenile age are more sensitive to stress (i.e. exercise or myocardial infarction, MI) and displayed sign of late-onset cardiotoxicity. Moreover, the post-MI survival of DOX-exposed mice was lower and these animals had a reduced neovascularization suggesting that DOX treatment puts the adult heart at higher risk for ischemic injury. Although MI was associated with the migration of progenitor cells into the damaged area, there were significantly fewer CPCs in the border zone of animals that had been exposed to DOX as pups. This study also suggested that juvenile DOX exposure affects differentiation of CPCs. Of note, DOX-exposed pups had significantly fewer CPCs, reinforcing the hypothesis that DOX might be harmful to these cells. CPC growth and telomerase activity were reduced while cell cycle inhibitor $\mathrm{p} 16^{\mathrm{INK} 4 \mathrm{a}}$ was upregulated. Therefore, juvenile exposure even to low dose of DOX induced senescence and might have permanently reduced the number of resident CPCs.

The possibility that cellular senescence can represent an early event also in the human heart is supported by the presence of high fraction of $\mathrm{p} 16^{\mathrm{INK} 4 \mathrm{a}}$-positive hCPCs in myocardium of anthracycline-treated patients with normal cardiac function that died of other complications during chemotherapy [57]. Because the early and late cellular adaptations that occur after treatment may differ, the evolution of the cellular and molecular effects of clinically relevant concentrations of DOX on hCPCs was studied in vitro. Early after exposure, DOX reduced 
hCPC viability, induced significant level of apoptosis and increased the expression of proteins involved in the DNA damage response such as phospho-ATM ${ }^{\text {Ser1981 }}$ kinase, $\gamma \mathrm{H} 2 \mathrm{AX}$ and phospho-p $53^{\text {Ser15 }}$ [57]. The activation of ATM coupled with the increase of $\gamma \mathrm{H} 2 \mathrm{AX}$ indicates DNA damage while the phosphorylation of p53 can activate apoptotic or cellular senescence pathways [64]. In DOX-treated hCPCs, the early increase in p53 phosphorylation triggered the late activation of apoptotic while the expression of $\mathrm{p} 16^{\mathrm{INK4a}}$ began to rise in parallel with the increased activity of SA- $\beta$-gal [57]. Similar cellular events can occur in the hearts of patients during or immediately after DOX administration. However, after removal of DOX, the rate of apoptotic death of hCPCs and the expression of proteins involved in DNA damage response (phospho-p53 ${ }^{\text {Ser15 }}$, phospho-ATM ${ }^{\text {Ser1981 }}$ ) returned to baseline. In the absence of other pro-senescence stimuli a cell could potentially resume its proliferative capacity [65] but this was not a case. The very high fraction of senescent cells indicated that hCPCs entered the irreversible phase of growth arrest after permanent activation of p16 $6^{\mathrm{INK} 4 \mathrm{a}}$ $\mathrm{Rb}$ pathway. In this scenario, a transient activation of p53 initiates the senescence response while $\mathrm{p} 16^{\mathrm{INK} 4 \mathrm{a}}$ operates to maintain this state representing a delayed cellular response $[64,66]$.

Although the reported phenomena per se may not directly lead to heart failure, they can make the myocardium of an apparently healthy person more vulnerable. The late onset of cardiomyopathy in patients, who already have sustained subclinical cardiac damage as a result of DOX chemotherapy, could be attributed to an additional pathological or physiological stress like ischemia, acute viral infection, exercise, pregnancy, or the increase of body mass in children during normal growth. These factors can transform the silent myopathy into overt heart failure [10, 67-69].

\section{Other cardiac cells \\ Cardiac fibroblasts}

Accumulation of fibrotic tissue is one of the features of DOX-cardiomyopathy triggered by the necrotic damage and its pro-inflammatory load, but also by the excessive ROS generation. The latter has been recognized as a strong stimulator of pathological collagen production as well as activator of transforming growth factor- $\beta$ (TGF- $\beta$ ), a cytokine that has been associated to fibro-inflammatory signaling [70-72]. In our model, DOX determined significant increases of TGF- $\beta$ and phospho-SMAD3 along with an increment of collagen deposition, and enhanced phenotypic transformation of fibroblasts to myofibroblasts, cells that express contractile proteins and secrete pro-fibrotic factors [73]. Interestingly, cardiac fibroblasts isolated from DOX-treated rats had elevated levels of TGF- $\beta$ and an

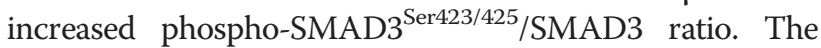

expression of fibroblast activate protein $1 \alpha$ and $\alpha$-SMA, markers of activated fibroblasts was also augmented. Additionally, DOX significantly upregulated two of the main components of the extracellular matrix, collagen type 1 and fibronectin [73]. Therefore, these results show that in vivo exposure to DOX generates pro-fibrotic population of activated cardiac fibroblasts. Surprisingly, the activated, pro-fibrotic phenotype of cardiac fibroblasts was preserved in vitro even after several passages, suggesting once again that the cell that has been stressed with DOX retains the "pharmacological signature" and transmits this state to the progeny. This intriguing phenomenon requires specific future investigations.

Finally, because fibroblasts play a role as supporting cells for CPCs within the niches, the potential damage produced by DOX can result in the derangement of the cardiac niche [74]. The biological role of myofibroblastendogenous stem cell interactions, in terms of cardiac fibrosis, remains unclear, although several studies suggest that also progenitor cells may influence extracellular matrix composition in a paracrine manner [75].

\section{Vascular cells}

Since both experimental and clinical studies reported that anthracycline toxicity may be also linked to the deleterious effects of these drugs on the endothelium [76], a brief examination of smooth muscle cells (SMCs) and endothelial cells has to be done. In particular, in vitro and ex-vivo studies evaluated SMCs responses to drug exposure. DOX-treated vascular SMCs were arrested in the G2/M phase of the cell cycle and a series of classical markers of cellular damage and senescence (i.e. SA- $\beta$-gal activity, DNA damage foci, changed morphology, and increased superoxide production) were observed [77]. Instead, organ-culture vascular tissue was used to examine the effects of DOX on the morphology and functions of SMCs. Interestingly, treatment with DOX decreased the $\alpha$ adrenoceptor protein and noradrenaline-induced contraction. The mediation of ROS was demonstrated by the partial restoration of $\alpha$ adrenoceptor expression and vessel contraction in presence of SOD [78]. Moreover, an in vitro study conducted on endothelial cells documented as both DOX and daunorubicin induced ROS-dependent cytotoxic effects, although with different potency due to their relative cellular accumulation [79].

\section{Extracardiac cells with progenitor properties}

As discussed above, the inhibition of the progenitor cellmediated self-repairing potential of the heart is considered one of the pathogenetic mechanisms of DOX-induced cardiomyopathy. Apart cardiac progenitors, also different cell types of extra-cardiac origin, such as bone marrow, could be taken into account to better understand pathophysiology 
of the heart after injury and to extend the knowledge about the role of stem cells in DOX-induced cardiomyopathy.

\section{Endothelial progenitor cells}

Bone marrow-derived endothelial progenitor cells (EPCs) can be mobilized to the peripheral circulation thus contributing to post-natal angiogenesis and vasculogenesis [80]. Recruitment of these cells was found to attenuate tissue damage in models of myocardial ischemia and anthracycline cardiomyopathy [81-83]. Also in patients, number of circulating EPCs has been seen to be predictive of cardiovascular diseases and may represent a better predictor of vascular reactivity than conventional cardiovascular risk factors [84]. Interestingly, in vitro studies reported dosedependent DOX toxicity on EPCs in which apoptosis was induced by high doses while low doses of DOX caused a premature senescence phenotype. Sub-cytotoxic dose of DOX produces ROS with the result of alteration in the expression of several proteins that regulate cell cycle, cytoskeletal and cellular architecture $[85,86]$. Oxidative stress may trigger the $\mathrm{p} 16^{\mathrm{INK4a}}$-pRb-dependent senescence involving p38 signalling [87]. EPCs exposed to sub-apoptotic doses of DOX undergo the activation of MAPKs p38 and JNK signalling, whose balance regulates senescence and apoptosis $[86,88,89]$. p38 and JNK pathways antagonistically control cellular senescence, $\mathrm{p} 16^{\mathrm{INK} 4 \mathrm{a}}$ expression and cytoskeletal organization in EPCs treated with DOX [86]. It is therefore possible that also in EPCs, ROS accumulation, induction of $\mathrm{p} 16^{\mathrm{INK} 4 \mathrm{a}}$ together with telomere dysfunction, suggested by the down regulation of TRF2, jointly contribute to DOX-induced senescence of this progenitor cell class leading to the failure of EPC-mediated regenerative processes. Of note, in an experimental model, DOXinduced nephropathy was associated with development of EPC senescence and incompetence that hampered their engraftment into the kidney, supporting the hypothesis that progenitor cells injured by DOX are, in part, responsible for the progression of the disease [90].

\section{Bone marrow cells}

In physiologic conditions, the trafficking of bone marrow cells (BMCs) to other organs is limited. However, after tissue damage, this process is amplified and a massive number of progenitor cells are released into the peripheral blood with the involvement of several mediators, such as granulocyte-colony stimulating factor (G-CSF), stromal cell-derived factor- 1 and vascular endothelial growth factor [91, 92]. It has been shown that also human heart can be the site of homing of BMCs and that cardiomyocytes and coronary vascular cells can be formed de novo in the adult life [93, 94]. Experimental models confirmed the possibility that BMCs can translocate from the marrow to the infarcted myocardium and contribute to the repair process [95]. Although a significant amount of clinical work has been published regarding the effect of the BMCs mobilization on the heart after an acute ischemic injury, inconclusive results have been achieved with divergent evidence reported about the possibility that G-CSFactivated BMCs may improve left ventricular ejection fraction or attenuate ventricular remodelling [96-98]. Of note, also in a mouse model of DOX cardiotoxicity, G-CSF has been used to mobilize BMCs for evaluation of their migration capacity towards the myocardium and their possible role in attenuating the cardiac dysfunction. G-CSF enhanced the migration of BMCs into the heart, attenuated cardiotoxicity and improved survival. Moreover, green fluorescent protein-labelled BMCs observed were structurally integrated in the myocardium and acquired a myocyte-like phenotype [99]. Although the clinical importance of the bone marrow mesenchymal stem cell (MSC)driven response to the cardiac damage is unknown, there is a consensus that MSCs can contribute directly and indirectly [100-102] to the repair of the damaged myocardium, and the clinical trials with MSCs and chronic ischemic heart failure are ongoing [103]. It should be pointed out that the bone marrow, although provided with an active population of stem cells, does (like any other system) fail under prolonged toxic injury. In this regard, given the cytotoxic properties of DOX, bone marrow toxicity represents the limiting factor during the treatment. When chemotherapeutic regimens disregard regular time intervals to allow the recovery of the hematopoietic system, bone marrow failure leads to life-threating intractable septic and haemorrhagic complications [104]. Therefore, it is reasonable to assume that bone marrow-derived stem cells "primed" with DOX undergo alterations that can interfere with their function also in other organs. In fact, it has been shown that DOX is toxic for MSCs $[105,106]$. In the view of potential clinical interest for MSCs, this observations need further investigation.

\section{Conclusions}

Although only a few studies addressing the role of cells other than cardiomyocytes are available, it is reasonable to assume that molecular events that occur at level of different cellular compartments contribute to development and progression of DOX cardiomyopathy. Additionally, independently from the molecular mechanisms through which DOX induces cellular damage, oxidative stress, DNA damage, senescence and apoptosis all happen and have an impact on myocardial homeostasis, although their relative weight can differ. Therefore, to facilitate the comprehension of the sequence of events emerging from the complex interaction of different forms of molecular stress, more detailed studies should address not only the role of each cell type but also the possibly different susceptibility of each cell. 
Adverse effects present long after the clearance of the drug and its metabolites remain another unresolved issue. A challenging hypothesis yet to be tested involves a phenomenon of biological memory, described as a persistent cellular response to a transitory stimulus. Cellular memory of past stimuli maintains cell identity even if the signal was experienced only once [107]. In addition to normal development, such phenomenon has also been described in diabetes when a cell "remembers" the onset of a hyperglycaemic peak [108]. In this view, an anthracycline can be considered as a pharmacological stressor that leaves its molecular signature in different cellular components probably through specific epigenetic changes. Interestingly, ROS have been proposed as one of the molecular keepers of metabolic memory [109] and take an undisputable part in cardiovascular diseases by modulating numerous cellular processes like cellular migration, proliferation and hypertrophy, angiogenesis, apoptosis and senescence, all of which contribute to cardiotoxicity. Therefore, although advanced knowledge of biological and cellular events implicated in the response of the heart to anti-cancer therapy is a fundamental tool, the further dissection of events should not drive our attention away from a central role of a ROS-driven processes that sustain an on-going damage and create a state of susceptibility. Thus, a broader cellular view presented here combined with ROS-modifying approaches could be a useful platform for new experimental and clinical cardioprotective strategies.

\section{Ethics approval and consent to participate Not applicable.}

\section{Consent for publication \\ Not applicable.}

\begin{abstract}
Abbreviation
BMCs: bone marrow cells; CPCs: cardiac progenitor cells; DOX: doxorubicin; EPCs: endothelial progenitor cells; G-CSF: granulocyte-colony stimulating factor; hCPCs: human cardiac progenitor cells; MI: myocardial infarction; MSCs: mesenchymal stem cells; ROS: reactive oxygen species; SMCs: smooth muscle cells; TGF- $\beta$ : transforming growth factor- $\beta$; $\gamma \mathrm{H} 2 \mathrm{AX}$ : phospho-histone $\mathrm{H} 2$.
\end{abstract}

\section{Competing interests}

The authors declare that they have no competing interest.

\section{Authors' contributions}

Study conception and design: ADA, KU, DC, FR and LB. Acquisition of data: $E P, L P C, A R$, RR, and GE. Analysis and interpretation of data: EP, LPC, AR, RR, and GE. Drafting of manuscript: ADA, KU and DC. Critical revision: ADA, KU, DC, FR and LB. All authors read and approved the final manuscript.

\section{Funding}

This work was supported by POR Campania FSE 2007/2013 Grant "Campania Research in Experimental Medicine-CREME" (CUP-B25B09000050007) and POR Campania FESR 2007/2013 Grant "MOdelli in VIvo di patologie umanE-MO.VI.E" (CUP-B25C13000240007).
Received: 8 February 2016 Accepted: 18 February 2016

Published online: 03 March 2016

\section{References}

1. Grein A, Spalla C, Di Marco A, Canevazzi G. Descrizione e classificazione di un attinomicete (streptomyces peucetius sp. nova) produttore di una sostanza ad attivita antitumorale-La Daunomicina. Giorn Microbiol. 1963:11:109-18.

2. Bonadonna G, Monfardini S, De Lena M, Fossati-Bellani F. Clinical evaluation of adriamycin, a new antitumour antibiotic. Br Med J. 1969;3:503-6.

3. Praga C, Beretta G, Vigo PL, Lenaz GR, Pollini C, Bonadonna G, et al. Adriamycin cardiotoxicity: a survey of 1273 patients. Cancer Treat Rep. 1979; 63:827-34.

4. Herman EH, Ferrans VJ, Jordan W, Ardalan B. Reduction of chronic daunorubicin cardiotoxicity by ICRF-187 in rabbits. Res Commun Chem Pathol Pharmacol. 1981;31:85-97.

5. Herman EH, el-Hage AN, Ferrans VJ, Ardalan B. Comparison of the severity of the chronic cardiotoxicity produced by doxorubicin in normotensive and hypertensive rats. Toxicol Appl Pharmacol. 1985;78:202-14.

6. Ewer M, Gianni L, Pane F, Sandri MT, Steiner RK, Wojnowski L, et al. Report on the international colloquium on cardio-oncology.

Ecancermedicalscience. 2014;8:433.

7. Lotrionte M, Biondi-Zoccai G, Abbate A, Lanzetta G, D'Ascenzo F, Malavasi V, et al. Review and meta-analysis of incidence and clinical predictors of anthracycline cardiotoxicity. Am J Cardiol. 2013;112:1980-4.

8. Cardinale D, Colombo A, Bacchiani G, Tedeschi I, Meroni CA, Veglia F, et al. Early detection of anthracycline cardiotoxicity and improvement with heart failure therapy. Circulation. 2015;131:1981-8

9. Armstrong GT, Joshi VM, Ness KK, Marwick TH, Zhang N, Srivastava D, et al. Comprehensive Echocardiographic detection of treatment-related cardiac dysfunction in adult survivors of childhood cancer: results from the St. Jude Lifetime cohort study. J Am Coll Cardiol. 2015;65:2511-22.

10. Lipshultz SE, Colan SD, Gelber RD, Perez-Atayde AR, Sallan SE, Sanders SP. Late cardiac effects of doxorubicin therapy for acute lymphoblastic leukemia in childhood. N Engl J Med. 1991;324:808-15.

11. DeSantis CE, Lin CC, Mariotto AB, Siegel RL, Stein KD, Kramer JL, et al. Cancer treatment and survivorship statistics, 2014. CA Cancer J Clin. 2014;64:252-71.

12. Lipshultz SE, Lipsitz SR, Sallan SE, Dalton VM, Mone SM, Gelber RD, et al. Chronic progressive cardiac dysfunction years after doxorubicin therapy for childhood acute lymphoblastic leukemia. J Clin Oncol. 2005;23:2629-36.

13. Minotti G, Menna P, Salvatorelli E, Cairo G, Gianni L. Anthracyclines: molecular advances and pharmacologic developments in antitumor activity and cardiotoxicity. Pharmacol Rev. 2004;56:185-229.

14. Legha SS, Benjamin RS, Mackay B, Yap HY, Wallace S, Ewer M, et al. Adriamycin therapy by continuous intravenous infusion in patients with metastatic breast cancer. Cancer. 1982:49:1762-6.

15. Menna P, Paz OG, Chello M, Covino E, Salvatorelli E, Minotti G. Anthracycline cardiotoxicity. Expert Opin Drug Saf. 2012;11:S21-36.

16. Lipshultz SE, Miller TL, Lipsitz SR, Neuberg DS, Dahlberg SE, Colan SD, et al. Continuous versus bolus infusion of doxorubicin in children with ALL: longterm cardiac outcomes. Pediatrics. 2012;130:1003-11.

17. Batist G. Cardiac safety of liposomal anthracyclines. Cardiovasc Toxicol. 2007; 7:72-4.

18. van Dalen EC, Michiels EM, Caron HN, Kremer LC. Different anthracycline derivates for reducing cardiotoxicity in cancer patients. Cochrane Database Syst Rev. 2010;17(3), CD005006. doi:10.1002/14651858.

19. Sieswerda E, Kremer LC, Caron HN, van Dalen EC. The use of liposomal anthracycline analogues for childhood malignancies: a systematic review. Eur J Cancer. 2011:47:2000-8.

20. Salvatorelli E, Menna P, Cantalupo E, Chello M, Covino E, Wolf Fl, et al. The concomitant management of cancer therapy and cardiac therapy. Biochim Biophys Acta. 1848;2015:2727-37.

21. Anderlini P, Benjamin RS, Wong FC, Kantarjian HM, Andreeff M, Kornblau SM, et al. Idarubicin cardiotoxicity: a retrospective study in acute myeloid leukemia and myelodysplasia. J Clin Oncol. 1995;13:2827-34.

22. Alderton PM, Gross J, Green MD. Comparative study of doxorubicin mitoxantrone, and epirubicin in combination with ICRF-187 (ADR-529) in a chronic cardiotoxicity animal model. Cancer Res. 1992;52:194-201.

23. Ryberg M, Nielsen D, Cortese G, Nielsen G, Skovsgaard T, Andersen PK. New insight into epirubicin cardiac toxicity: competing risks analysis of 1097 breast cancer patients. J Natl Cancer Inst. 2008;100:1058-67. 
24. Lipshultz SE, Scully RE, Lipsitz SR, Sallan SE, Silverman LB, Miller TL, et al. Assessment of dexrazoxane as a cardioprotectant in doxorubicin-treated children with high-risk acute lymphoblastic leukaemia: long-term follow-up of a prospective, randomised, multicentre trial. Lancet Oncol. 2010;11:950-61.

25. Speyer JL, Green MD, Zeleniuch-Jacquotte A, Wernz JC, Rey M, Sanger J, et al. ICRF-187 permits longer treatment with doxorubicin in women with breast cancer. J Clin Oncol. 1992;10:117-27.

26. Hochster HS. Clinical pharmacology of dexrazoxane. Semin Oncol. 1998;25: 37-42.

27. Lyu YL, Kerrigan JE, Lin CP, Azarova AM, Tsai YC, Ban Y, et al. Topoisomerase Ilbeta mediated DNA double-strand breaks: implications in doxorubicin cardiotoxicity and prevention by dexrazoxane. Cancer Res. 2007;67:8839-46.

28. Swain SM, Whaley FS, Gerber MC, Ewer MS, Bianchine JR, Gams RA. Delayed administration of dexrazoxane provides cardioprotection for patients with advanced breast cancer treated with doxorubicin-containing therapy. J Clin Oncol. 1997;15:1333-40.

29. Tebbi CK, London WB, Friedman D, Villaluna D, De Alarcon PA, Constine LS, et al. Dexrazoxane-associated risk for acute myeloid leukemia/ myelodysplastic syndrome and other secondary malignancies in pediatric Hodgkin's disease. J Clin Oncol. 2007;25:493-500.

30. Vrooman LM, Neuberg DS, Stevenson KE, Asselin BL, Athale UH, Clavell L, et al. The low incidence of secondary acute myelogenous leukaemia in children and adolescents treated with dexrazoxane for acute lymphoblastic leukaemia: a report from the Dana-Farber Cancer Institute ALL Consortium. Eur J Cancer. 2011;47:1373-9.

31. Salvatorelli E, Menna P, Minotti G. Managing anthracycline-induced cardiotoxicity: beginning with the end in mind. Future Cardiol. 2015;11:363-6.

32. Lipshultz SE, Franco VI, Sallan SE, Adamson PC, KSteiner R, Swain SM, et al. Dexrazoxane for reducing anthracycline-related cardiotoxicity in children with cancer: An update of the evidence. Progr Pediatr Cardiol. 2014;36:39-49.

33. Ladas EJ, Jacobson JS, Kennedy DD, Teel K, Fleischauer A, Kelly KM. Antioxidants and cancer therapy: a systematic review. J Clin Oncol. 2004;22:517-28.

34. Gianni L, Herman EH, Lipshultz SE, Minotti G, Sarvazyan N, Sawyer DB. Anthracycline cardiotoxicity: from bench to bedside. J Clin Oncol. 2008;26: 3777-84.

35. Kalay N, Basar E, Ozdogru I, Er O, Cetinkaya Y, Dogan A, et al. Protective effects of carvedilol against anthracycline-induced cardiomyopathy. J Am Coll Cardiol. 2006:48:2258-62.

36. Kaya MG, Ozkan M, Gunebakmaz O, Akkaya H, Kaya EG, Akpek M, et al. Protective effects of nebivolol against anthracycline-induced cardiomyopathy: a randomized control study. Int J Cardiol. 2013;167:2306-10.

37. Spallarossa P, Garibaldi S, Altieri P, Fabbi P, Manca V, Nasti S, et al. Carvedilol prevents doxorubicin-induced free radical release and apoptosis in cardiomyocytes in vitro. J Mol Cell Cardiol. 2004;37:837-46.

38. Mason RP, Kalinowski L, Jacob RF, Jacoby AM, Malinski T. Nebivolol reduces nitroxidative stress and restores nitric oxide bioavailability in endothelium of black Americans. Circulation. 2005;112:3795-801.

39. Singal PK, Li T, Kumar D, Danelisen I, lliskovic N. Adriamycin-induced heart failure: mechanism and modulation. Mol Cell Biochem. 2000;207:77-86.

40. Corradi F, Paolini L, De Caterina R. Ranolazine in the prevention of anthracycline cardiotoxicity. Pharmacol Res. 2014;79:88-102.

41. Octavia Y, Tocchetti CG, Gabrielson KL, Janssens S, Crijns HJ, Moens AL. Doxorubicin-induced cardiomyopathy: from molecular mechanisms to therapeutic strategies. J Mol Cell Cardiol. 2012;52:1213-25.

42. Prezioso L, Tanzi S, Galaverna F, Frati C, Testa B, Savi M, et al. Cancer treatment-induced cardiotoxicity: a cardiac stem cell disease? Cardiovasc Hematol Agents Med Chem. 2010;8:55-75.

43. Bearzi C, Rota M, Hosoda T, Tillmanns J, Nascimbene A, De Angelis A, et al. Human cardiac stem cells. Proc Natl Acad Sci U S A. 2007;104:14068-73.

44. Beltrami AP, Barlucchi L, Torella D, Baker M, Limana F, Chimenti S, et al. Adult cardiac stem cells are multipotent and support myocardial regeneration. Cell. 2003;114:763-76.

45. Pfister O, Mouquet F, Jain M, Summer R, Helmes M, Fine A, et al. CD31- but not CD31 ? cardiac side population cells exhibit functional cardiomyogenic differentiation. Circ Res. 2005;97:52-61.

46. Smith RR, Barile L, Cho HC, Leppo MK, Hare JM, Messina E, et al. Regenerative potential of cardiosphere-derived cells expanded from percutaneous endomyocardial biopsy specimens. Circulation. 2007;115:896-908.

47. Cesselli D, Beltrami AP, D'Aurizio F, Marcon P, Bergamin N, Toffoletto B, et al. Effects of age and heart failure on human cardiac stem cell function. Am J Pathol. 2011;179:349-66.
48. Chimenti C, Kajstura J, Torella D, Urbanek K, Heleniak H, Colussi C, et al. Senescence and death of primitive cells and myocytes lead to premature cardiac aging and heart failure. Circ Res. 2003;93:604-13.

49. Rota M, LeCapitaine N, Hosoda T, Boni A, De Angelis A, Padin-Iruegas ME, et al. Diabetes promotes cardiac stem cell aging and heart failure, which are prevented by deletion of the p66shc gene. Circ Res. 2006;99:42-52.

50. Rupp S, Bauer J, von Gerlach S, Fichtlscherer S, Zeiher AM, Dimmeler S, Schranz D. Pressure overload leads to an increase of cardiac resident stem cells. Basic Res Cardiol. 2012;107:252.

51. Urbanek K, Torella D, Sheikh F, De Angelis A, Nurzynska D, Silvestri F, et al. Myocardial regeneration by activation of multipotent cardiac stem cells in ischemic heart failure. Proc Natl Acad Sci U S A. 2005;102:8692-7.

52. Avolio E, Gianfranceschi G, Cesselli D, Caragnano A, Athanasakis E, Katare R, et al. Ex vivo molecular rejuvenation improves the therapeutic activity of senescent human cardiac stem cells in a mouse model of myocardial infarction. Stem Cells. 2014;32:2373-85.

53. Gonzalez A, Rota M, Nurzynska D, Misao Y, Tillmanns J, Ojaimi C, et al. Activation of cardiac progenitor cells reverses the failing heart senescent phenotype and prolongs lifespan. Circ Res. 2008;102:597-606.

54. Kajstura J, Gurusamy N, Ogorek B, Goichberg P, Clavo-Rondon C, Hosoda T, et al. Myocyte turnover in the aging human heart. Circ Res. 2010;107:1374-86.

55. Huang C, Zhang X, Ramil JM, Rikka S, Kim L, Lee Y, et al. Juvenile exposure to anthracyclines impairs cardiac progenitor cell function and vascularization resulting in greater susceptibility to stress-induced myocardial injury in adult mice. Circulation. 2010;121:675-83.

56. De Angelis A, Piegari E, Cappetta D, Marino L, Filippelli A, Berrino L, et al. Anthracycline cardiomyopathy is mediated by depletion of the cardiac stem cell pool and is rescued by restoration of progenitor cell function. Circulation. 2010;121:276-92.

57. Piegari E, De Angelis A, Cappetta D, Russo R, Esposito G, Costantino S, et al. Doxorubicin induces senescence and impairs function of human cardiac progenitor cells. Basic Res Cardiol. 2013;108:334

58. De Angelis A, Piegari E, Cappetta D, Russo R, Esposito G, Ciuffreda LP, et al. SIRT1 activation rescues doxorubicin-induced loss of functional competence of human cardiac progenitor cells. Int J Cardiol. 2015;189:30-44.

59. D'Amario D, Cabral-Da-Silva MC, Zheng H, Fiorini C, Goichberg P, Steadman $\mathrm{E}$, et al. Insulin-like growth factor-1 receptor identifies a pool of human cardiac stem cells with superior therapeutic potential for myocardial regeneration. Circ Res. 2011;108:1467-81.

60. Linke A, Muller P, Nurzynska D, Casarsa C, Torella D, Nascimbene A, et al. Stem cells in the dog heart are self-renewing, clonogenic, and multipotent and regenerate infarcted myocardium, improving cardiac function. Proc Natl Acad Sci U S A. 2005;102:8966-71.

61. Torella D, Rota M, Nurzynska D, Musso E, Monsen A, Shiraishi I, et al. Cardiac stem cell and myocyte aging, heart failure, and insulin-like growth factor-1 overexpression. Circ Res. 2004;94:514-24.

62. Urbanek K, Rota M, Cascapera S, Bearzi C, Nascimbene A, De Angelis A, et al Cardiac stem cells possess growth factor-receptor systems that after activation regenerate the infarcted myocardium, improving ventricular function and long-term survival. Circ Res. 2005;97:663-73.

63. Powell EM, Mars WM, Levitt P. Hepatocyte growth factor/scatter factor is a motogen for interneurons migrating from the ventral to dorsal telencephalon. Neuron. 2001;30:79-89.

64. Campisi J. Senescent cells, tumor suppression, and organismal aging: good citizens, bad neighbours. Cell. 2005;120:513-22.

65. Beausejour CM, Krtolica A, Galimi F, Narita M, Lowe SW, Yaswen P, Campisi J. Reversal of human cellular senescence: roles of the p53 and p16 pathways. EMBO J. 2003;22:4212-22.

66. Takai H, Smogorzewska A, de Lange T. DNA damage foci at dysfunctional telomeres. Curr Biol. 2003;13:1549-56.

67. Ali MK, Ewer MS, Gibbs HR, Swafford J, Graff KL. Late doxorubicin-associated cardiotoxicity in children. The possible role of intercurrent viral infection. Cancer. 1994;74:182-8.

68. Chen MH, Colan SD, Diller L. Cardiovascular disease: cause of morbidity and mortality in adult survivors of childhood cancers. Circ Res. 2011;108:619-28.

69. Pai VB, Nahata MC. Cardiotoxicity of chemotherapeutic agents: incidence, treatment and prevention. Drug Saf. 2000;22:263-302.

70. Kuwahara F, Kai H, Tokuda K, Kai M, Takeshita A, Egashira K, et al. Transforming growth factor-beta function blocking prevents myocardial fibrosis and diastolic dysfunction in pressure-overloaded rats. Circulation. 2002;106:130-5 
71. Krstić J, Trivanović D, Mojsilović S, Santibanez JF. Transforming growth factor-beta and oxidative stress interplay: implications in tumorigenesis and cancer progression. Oxid Med Cell Longev. 2015;2015:654594.

72. Li AH, Liu PP, Villarreal FJ, Garcia RA. Dynamic changes in myocardia matrix and relevance to disease: translational perspectives. Circ Res. 2014; 114:916-27.

73. Cappetta D, Esposito G, Piegari E, Russo R, Ciuffreda LP, Rivellino A, et al. SIRT1 activation attenuates diastolic dysfunction by reducing cardiac fibrosis in a model of anthracycline cardiomyopathy. Int J Cardiol. 2015;205:99-110.

74. Urbanek K, Cesselli D, Rota M, Nascimbene A, De Angelis A, Hosoda T, et al. Stem cell niches in the adult mouse heart. Proc Natl Acad Sci U S A. 2006; 103:9226-31.

75. Ramkisoensing AA, de Vries AA, Atsma DE, Schalij MJ, Pijnappels DA. Interaction between myofibroblasts and stem cells in the fibrotic heart: balancing between deterioration and regeneration. Cardiovasc Res. 2014; 102:224-31.

76. Soultati A, Mountzios G, Avgerinou C, Papaxoinis G, Pectasides D, Dimopoulos MA, Papadimitriou C. Endothelial vascular toxicity from chemotherapeutic agents: preclinical evidence and clinical implications. Cancer Treat Rev. 2012;38:473-83.

77. Bielak-Zmijewska A, Wnuk M, Przybylska D, Grabowska W, Lewinska A, Alster $\mathrm{O}$, et al. A comparison of replicative senescence and doxorubicin-induced premature senescence of vascular smooth muscle cells isolated from human aorta. Biogerontology. 2014;15:47-64.

78. Murata T, Yamawaki H, Hori M, Sato K, Ozaki H, Karaki H. Chronic vascular toxicity of doxorubicin in an organ-cultured artery. Br J Pharmacol. 2001;132: 1365-73.

79. Wojcik T, Buczek E, Majzner K, Kolodziejczyk A, Miszczyk J, Kaczara P, et al. Comparative endothelial profiling of doxorubicin and daunorubicin in cultured endothelial cells. Toxicol In Vitro. 2015;29:512-21.

80. Urbich C, Dimmeler S. Endothelial progenitor cells: characterization and role in vascular biology. Circ Res. 2004;95:343-53.

81. Rafii S, Lyden D. Therapeutic stem and progenitor cell transplantation for organ vascularization and regeneration. Nat Med. 2003;9:702-12.

82. Hamed S, Barshack I, Luboshits G, Wexler D, Deutsch V, Keren G, George J. Erythropoietin improves myocardial performance in doxorubicin-induced cardiomyopathy. Eur Heart J. 2006;27:1876-83.

83. Takahashi T, Kalka C, Masuda H, Chen D, Silver M, Kearney M, et al. Ischemia- and cytokine-induced mobilization of bone marrow-derived endothelial progenitor cells for neovascularization. Nat Med. 1999;5:434-8.

84. Hill JM, Zalos G, Halcox JP, Schenke WH, Waclawiw MA, Quyyumi AA, Finkel T. Circulating endothelial progenitor cells, vascular function, and cardiovascular risk. N Engl J Med. 2003;348:593-600.

85. Maejima Y, Adachi S, Ito H, Hirao K, Isobe M. Induction of premature senescence in cardiomyocytes by doxorubicin as a novel mechanism of myocardial damage. Aging Cell. 2008;7:125-36

86. Spallarossa P, Altieri P, Barisione C, Passalacqua M, Aloi C, Fugazza G, et al. p38 MAPK and JNK antagonistically control senescence and cytoplasmic p16INK4A expression in doxorubicin-treated endothelial progenitor cells. PLoS One. 2010;5, e15583.

87. Deng Q, Liao R, Wu BL, Sun P. High intensity ras signaling induces premature senescence by activating p38 pathway in primary human fibroblasts. J Biol Chem. 2004:279:1050-9.

88. Wada T, Stepniak E, Hui L, Leibbrandt A, Katada T, Nishina H, et al. Antagonistic control of cell fates by JNK and p38-MAPK signaling. Cell Death Differ. 2008;15:89-93.

89. Spallarossa P, Altieri P, Pronzato P, Aloi C, Ghigliotti G, Barsotti A, Brunelli C. Sublethal doses of an anti-erbB2 antibody leads to death by apoptosis in cardiomyocytes sensitized by low prosenescent doses of epirubicin: the protective role of dexrazoxane. J Pharmacol Exp Ther. 2010;332:87-96.

90. Yasuda K, Park HC, Ratliff B, Addabbo F, Hatzopoulos AK, Chander P, Goligorsky MS. Adriamycin nephropathy: a failure of endothelial progenitor cell-induced repair. Am J Pathol. 2010;176:1685-95.

91. Moore MA, Hattori K, Heissig B, Shieh JH, Dias S, Crystal RG, Rafii S. Mobilization of endothelial and hematopoietic stem and progenitor cells by adenovector-mediated elevation of serum levels of SDF-1, VEGF, and angiopoietin-1. Ann N Y Acad Sci. 2001;938:36-45.

92. McNiece IK, Briddell RA, Hartley CA, Smith KA, Andrews RG. Stem cell factor enhances in vivo effects of granulocyte colony stimulating factor for stimulating mobilization of peripheral blood progenitor cells. Stem Cells. 1993;11:36-41.
93. Quaini F, Urbanek K, Beltrami AP, Finato N, Beltrami CA, Nadal-Ginard B, et al. Chimerism of the transplanted heart. N Engl J Med. 2002;346:5-15.

94. Thiele J, Varus E, Wickenhauser C, Kvasnicka HM, Metz KA, Beelen DW. Regeneration of heart muscle tissue: quantification of chimeric cardiomyocytes and endothelial cells following transplantation. Histol Histopathol. 2004;19:201-9.

95. Fukuhara S, Tomita S, Nakatani T, Ohtsu Y, Ishida M, Yutani C, Kitamura S. G-CSF promotes bone marrow cells to migrate into infarcted mice heart, and differentiate into cardiomyocytes. Cell Transplant. 2004;13:741-8.

96. Moazzami K, Roohi A, Moazzami B. Granulocyte colony stimulating factor therapy for acute myocardial infarction. Cochrane Database Syst Rev. 2013;5, CD008844.

97. Achilli F, Malafronte C, Lenatti L, Gentile F, Dadone V, Gibelli G, et al. Granulocyte colony-stimulating factor attenuates left ventricular remodelling after acute anterior STEMI: results of the single-blind, randomized, placebocontrolled multicentre STem cEll Mobilization in Acute Myocardial Infarction (STEM-AMI) Trial. Eur J Heart Fail. 2010;12:1111-21.

98. San Roman JA, Sánchez PL, Villa A, Sanz-Ruiz R, Fernandez-Santos ME, Gimeno F, et al. Comparison of Different Bone Marrow-Derived Stem Cell Approaches in Reperfused STEMI. A Multicenter, Prospective, Randomized, Open-Labeled TECAM Trial. J Am Coll Cardiol. 2015;65:2372-82.

99. Tomita S, Ishida M, Nakatani T, Fukuhara S, Hisashi Y, Ohtsu Y, et al. Bone marrow is a source of regenerated cardiomyocytes in doxorubicin-induced cardiomyopathy and granulocyte colony-stimulating factor enhances migration of bone marrow cells and attenuates cardiotoxicity of doxorubicin under electron microscopy. J Heart Lung Transplant. 2004;23:577-84.

100. Nagaya N, Fujii T, Iwase T, Ohgushi H, Itoh T, Uematsu M, et al. Intravenous administration of mesenchymal stem cells improves cardiac function in rats with acute myocardial infarction through angiogenesis and myogenesis. Am J Physiol Heart Circ Physiol. 2004;287:H2670-6.

101. Gnecchi M, Zhang Z, Ni A, Dzau VJ. Paracrine mechanisms in adult stem cell signaling and therapy. Circ Res. 2008;103:1204-19.

102. Danieli P, Malpasso G, Ciuffreda MC, Cervio E, Calvillo L, Copes F, et al. Conditioned medium from human amniotic mesenchymal stromal cells limits infarct size and enhances angiogenesis. Stem Cells Transl Med. 2015;4:448-58.

103. Mushtaq M, DiFede DL, Golpanian S, Khan A, Gomes SA, Mendizabal A, et al. Rationale and design of the Percutaneous Stem Cell Injection Delivery Effects on Neomyogenesis in Dilated Cardiomyopathy (the POSEIDON-DCM study): a phase $|/| I$, randomized pilot study of the comparative safety and efficacy of transendocardial injection of autologous mesenchymal stem cell vs. allogeneic mesenchymal stem cells in patients with non-ischemic dilated cardiomyopathy. J Cardiovasc Transl Res. 2014;7:769-80.

104. Urbanek K, Frati C, Graiani G, Madeddu D, Falco A, Cavalli S, et al. Cardioprotection by Targeting the Pool of Resident and Extracardiac Progenitors. Curr Drug Targets. 2015;16:884-94.

105. Yang F, Chen H, Liu Y, Yin K, Wang Y, Li X, et al. Doxorubicin caused apoptosis of mesenchymal stem cells via p38, JNK and p53 pathway. Cell Physiol Biochem. 2013;32:1072-82.

106. Oliveira MS, Carvalho JL, Campos AC, Gomes DA, de Goes AM, Melo MM. Doxorubicin has in vivo toxicological effects on ex vivo cultured mesenchymal stem cells. Toxicol Lett. 2014;224:380-6.

107. Burrill DR, Silver PA. Making cellular memories. Cell. 2010;140:13-8.

108. Intine RV, Sarras Jr MP. Metabolic memory and chronic diabetes complications: potential role for epigenetic mechanisms. Curr Diab Rep. 2012;12:551-9.

109. Rajasekar P, O'Neill CL, Eeles L, Stitt AW, Medina RJ. Epigenetic changes in Endothelial progenitors as a possible cellular basis for glycemic memory in diabetic vascular complications. J Diabetes Res. 2015;2015:436879. 